\title{
THE NIGHT IS DARKEST JUST BEFORE THE DAWN: BATMAN E GOTHAM
}

\author{
The night is darkest just before the dawn: Batman and Gotham
}

José Duarte (Universidade de Lisboa - CEAUL/FCT)

\begin{abstract}
RESUMO: Desde a sua criação em 1939 que Batman teve diferentes representações. O mesmo acontece com a cidade que o acolhe: Gotham, pois ambos são indissociáveis. As várias transformações ocorridas quer no protagonista principal, quer na cidade, são particularmente notórias nas inúmeras adaptações televisivas/cinematográficas feitas ao longo do tempo. Desde a década de 40 do século XX, passando pela série dos anos 60, até às adaptações de Burton, Schumacher ou, mais recentemente, à trilogia de Christopher Nolan, Batman e Gotham sofreram transformações que são produtos do seu tempo. O presente estudo pretende apresentar uma breve reflexão sobre algumas destas adaptações, com especial atenção à relação do protagonista principal com a cidade. Neste sentido, será dada especial ênfase aos três últimos filmes que exploram, de modo bastante evidente, os acontecimentos resultantes dos ataques terroristas do 11 de Setembro de 2001 e as suas consequências. Assim, este ensaio divide-se em dois momentos essenciais. Num primeiro momento, será estabelecida a relação entre Batman e Gotham (entre corpo e cidade) e será apresentada uma breve leitura desta relação considerando algumas adaptações chave nas décadas seguintes ao aparecimento do super-herói. Numa segunda fase, é feita uma análise da trilogia de Nolan, tendo em conta os aspectos acima mencionados. Deste modo, a breve reflexão aqui apresentada tentará focar-se na evolução e simbologia de Gotham e Batman ao longo do tempo.
\end{abstract}

PALAVRAS-CHAVE: Batman; Gotham; Corpo; Cidade; Cinema.

\begin{abstract}
Since its creation in 1939, Batman has had different representations. The same applies to the city that hosts its hero: Gotham, as both are intimately linked. The various transformations that the main protagonist suffered, as well as the city, are particularly noticeable in numerous television/ film adaptations created over time. Beginning in the 1940s, from the TV series of the 60s, to the Burton and Schumacher adaptations or, more recently, Christopher Nolan's trilogy, Batman and Gotham suffered transformations that are products of their time. The purpose of this study is to present a brief reflection on some of these changes, with special attention given to the relationship between the main protagonist and the city. In this sense, special emphasis will be given to the last three films that explore, in a very clear way, the events resulting from the terrorist attacks of September 11, 2001 and its consequences. Thus, this paper is divided into two essential parts. The first part establishes the relationship between Batman and Gotham (between body and city) and presents a brief reading of this relationship taking into account some key adaptations in the decades following the appearance of the superhero. In the second part, I present an analysis of the The Dark Knight trilogy, taking into account the issues mentioned above. All in all, the short reflection presented here attempts to focus on the evolution and meaning of Gotham and Batman over time.
\end{abstract}

KEYWORDS: Batman; Gotham; Body; City; Cinema. 
Joker: Introduce a little anarchy. Upset the established order, and everything becomes chaos. I'm an agent of chaos. Oh, and you know the thing about chaos? It's fair! (The Dark Knight, 2008)

\section{Introdução: quem é Batman?}

Criado em 1939 pelas mãos de Bob Kane e Bill Finger, o super-herói ficcional Batman surgiu pela primeira vez em Detective Comics\#27, publicado pela DC Comics. A estreia do herói negro tornou-se numa das publicações mais importantes daquele período, seguindo o sucesso de Superman, publicado um ano antes. A partir desse momento, as histórias do vigilante da noite (Batman)/milionário extravagante (Bruce Wayne) tomaram diferentes direcções durante os seus 75 anos de existência, resultando em mais de 4000 histórias publicadas (BURKE, 2015, p. 13).

Para além das inúmeras histórias, Batman também deu origem a diversas adaptações televisivas/cinematográficas - com várias personagens, que vão desde alguns vilões até ao seu parceiro Robin - onde tem vindo a ser bem sucedido, quer do ponto de vista da crítica, quer do ponto de vista dos espectadores. De acordo com Will Brooker (2000, p. 33), no livro Batman Unmasked: analyzing a cultural icon, parte deste interesse em Batman deve-se à sua fluidez da personagem, uma vez que teve grande facilidade em adaptar-se às várias mudanças sucedidas nos últimos 70 anos.

Ao mesmo tempo, esta relevância cultural deve-se também àquilo que ele representa enquanto super-herói: 1) representa a luta contra o mal, colocando-se como o último reduto ante a possibilidade do caos permanente; 2) representa o comprometimento com a justiça[1]; e 3) é uma das mais complexas personagens a surgir em banda desenhada. Tal como referem White e Arp, a figura de Batman é cativante para um grande número de pessoas porque:

[...] he is "just" a human being, even though he is nothing like the rest of us. He has devoted his entire life to avenging the death of his parents and all other victims of crime by risking life and limb to protect his city of Gotham and beyond. He has spent years and sacrificed everything to train his body and his mind to the point of perfection. He is wealthy beyond measure, but denies himself all luxuries in pursuit of a goal that will never be attained. (2008, p. 1-2)

Assim, como os autores referem, existe uma grande empatia entre leitores/espectadores e Batman, em especial porque este último, ao contrário de muitos outros super-heróis, se aproxima de nós. Paralelamente, a cidade que acolhe Batman é, 
também ela, indissociável do super-herói, pois é responsável pela sua criação. Gotham é ao mesmo tempo uma cidade real e ficcionada que acolhe e produz corpos fantásticos, como é o caso de Batman ou dos seus arqui-inimigos.

Esta flexibilidade quer de Batman quer de Gotham fazem com quem ambos sejam objectos de grande interesse para explorar os momentos de tensão próprios de cada período, sem que algumas das questões centrais que envolvem a história original se percam. Desde a década de 40 do século XX, passando pela série dos anos 60, até às adaptações de Burton, Schumacher ou, mais recentemente, à trilogia de Christopher Nolan, Batman e Gotham sofreram transformações que são produtos do seu tempo. É de especial interesse para este estudo a relação de Batman com a cidade de Gotham nas suas representações televisivas/cinematográficas. Neste sentido, apesar de ser afectuada uma breve reflexão acerca de produções anteriores, será dado especial ênfase à trilogia de Nolan que explora, de modo bastante evidente, os acontecimentos resultantes dos ataques terroristas do 11 de Setembro de 2001 e as suas consequências.

Este estudo divide-se em dois momentos essenciais. Num primeiro momento, será estabelecida a relação entre Batman e Gotham (entre corpo e cidade) e apresentada uma breve leitura desta relação considerando algumas adaptações chave nas décadas seguintes ao aparecimento do super-herói. Na segunda parte é feita uma breve análise da trilogia de Nolan, tendo em conta os aspectos acima mencionados. Deste modo, a reflexão aqui apresentada tentará focar-se na evolução e simbologia de Gotham e Batman ao longo do tempo.

\section{O início de Gotham é também o início de Batman}

Num livro intitulado Comics and the City, Jorn Ahrens e Arno Meteling (2010, p. 5) atentam no facto de haver uma clara relação entre banda desenhada e a grande cidade enquanto espaço de vivência moderno. Esta ligação é particularmente evidente no caso de Batman, onde o espaço urbano tem um papel preponderante no desenvolvimento do protagonista e da história. Gotham é, tal como o próprio Batman, alvo de muitas leituras. A nível das adaptações, Liam Burke (2015, p. 14) esclarece que, no caso da banda desenhada, os realizadores e outros artistas criativos usam uma imagética e espaço específicos, mas nunca apenas uma história em particular preferindo, ao invés, narrativas distintas para criar uma nova história que seja identificável quer com o universo do trabalho original, quer com a audiência. 
Contudo, em alguns casos, a visão dos realizadores e artistas é influenciada por obras cuja importância não pode ser ignorada, como é o exemplo de The Dark Knight Returns (1986) de Frank Miller que, juntamente com Watchmen de Alan Moore e Dave Gibbons, iniciaria aquela que é considerada a Idade Moderna da banda desenhada. A criação de Miller viria a ser uma fonte de inspiração[2] para, entre outros, o realizador Tim Burton, responsável por dois filmes sobre Batman, Batman (1989) e Batman Returns (1992).

As diferentes adaptações são também produto do seu tempo e respondem a momentos muito específicos, o que faz com que grande parte destas obras se relacionem culturalmente com a sociedade onde estão inseridas. É o caso da trilogia Batman, de Christopher Nolan, que reflecte sobre a ansiedade no espaço urbano pós-11 de Setembro. De forma a compreender melhor esta relação e outras, é necessário um olhar mais atento à história de Batman e Gotham no ecrã.

Contrariamente a outras histórias de super-heróis, a história de Batman, tal como acontece com Superman, situa-se numa localização específica: Gotham. De acordo com William Uricchio (2010, p. 120), Gotham é mais do que simplesmente o espaço urbano onde Bruce Wayne/Batman luta contra o crime, uma vez que é também o local onde vários outros problemas económicos e sociais existem: "the city itself is a generator of social inequalities such as poverty, poor living conditions, inadequate education, corruption, and the absence of opportunity" (idem). O que o autor tenta sublinhar é a ideia de que Gotham produz vários sentidos: é acima de tudo uma cidade fictícia habitada por várias personagens - heróis, vilões ou gente comum -, mas também uma representação da realidade social urbana.

Da mesma forma que as cidades reais sofrem transformações, também Gotham foi sendo modificada por vários artistas para acomodar uma cartografia que fosse reflexo dos vários dilemas das cidades reais, como nota ainda Urrichio:

[...] the representation of the city undulated depression and urban decay; war and the need to look beyond urban conditions in the interests of fighting a larger enemy; the postwar era with its reorientation to civilian and above all family life; the uncertainties of the 1960s and 1970s manifest in the counterculture; the camp and beyond; the gritty 1980s marked by media representations of urban crime, governmental corruption; and the steady slide into darker, more obsessive concerns that have continued to the present. (2010, p. 122)

De facto, uma pesquisa rápida online por Gotham City ilustra as inúmeras faces que a cidade possui: existem descrições exaustivas da sua história, origem, residentes 
notáveis, ou edifícios conhecidos. É também possível explorar a sua geografia num mapa detalhado, para além dos muitos websites criados por fãs com diversas teorias, o que contribui para a multiplicidade de interpretações acerca da cidade. Tradicionalmente, Gotham surge associada a Nova Iorque ${ }^{[3]}$, em particular dado a sua geografia e ambiente. A cidade criada por Bill Finger teve grande influência do género noir, especialmente pela forma como explora um certo sentido de alienação, violência e corrupção no espaço urbano. O autor Frank Miller chegou mesmo a afirmar numa entrevista que Gotham contrastava com Metropolis, ambas diferentes versões de Nova Iorque. Se a cidade habitada pelo Super-Homem representava Nova Iorque de dia, a cidade de Batman era a versão nocturna e obscura do mesmo espaço.

Contudo, embora Gotham City seja comummente encarada como a versão ficcionada de Nova Iorque (COGLE, 2014, p. 3), alguns autores também estabelecem ligação entre Gotham e Chicago, em especial o período da década de 40 do século XX: uma cidade violenta e controlada por gangsters. A nível cinematográfico, por exemplo, Gotham tem vindo a ser representada por várias cidades mundiais: Nova Iorque ou Chicago, mas também Los Angeles, Londres ou Tokyo. Estas ilustram não só as diferentes associações estabelecidas entre Gotham e as cidades reais, mas também escolhas criativas dos realizadores. O mesmo aconteceu quer com Batman quer com os vilões contra quem este lutava. Note-se que Gotham é responsável pelo aparecimento de Batman e, do mesmo modo que esta se foi alterando, o mesmo aconteceu com os corpos fantásticos que a habitavam/habitam.

Assim, desde as primeiras adaptações, 1943, 1949 e 1960 respectivamente[ ${ }^{[4]}$, até à mais recente aventura cinematográfica do homem-morcego pela mão de Christopher Nolan que tanto a cidade como o super-herói têm vindo a ser transformados. Apesar de as primeiras criações serem de grande interesse cultural, este estudo inicia a breve análise começando no filme de 1966, dirigido por Leslie H. Martinson. Esta conhecida adaptação tinha como principais protagonistas Batman (Adam West) e Robin (Burt Ward) e destaca-se por revelar uma cidade que em muito se assemelha a Los Angeles, dado as cenas terem sido filmadas em estúdio. O filme foi também influenciado pela série criada por Lorenzo Semple Jr., onde o tom leve e camp prevalecia: o exagero nas cores dos fatos dos super-heróis, bem como em quase todo o cenário, a utilização da música ou o facto do filme estar caracterizado como aventura ou comédia são alguns exemplos. Esta era uma cidade esteticamente distante da criação original onde o seu super-herói e até mesmo vilões possuíam uma dimensão física e psicológica pouco 
acentuada. Nesta adaptação, as cores exageradas, a imagem da cidade e os corpos fantásticos que a habitam são resultado de um espaço criado e configurado com um estética pop, orientada para o consumo massificado, como nota Emliy Pugh (2014, p. 224).

Apesar do sucesso comercial do filme, foram feitos esforços para afastar a imagem de Batman de uma estética pop, de forma a fazer regressar o super-herói e a cidade às origens, i.e., com uma dimensão obscura influenciada pelo ambiente noir. The Dark Knight Returns (1986), de Frank Miller, viria a ter grande importância nesta mudança, uma vez que adoptou um lado mais obscuro para Gotham e, consequentemente para Batman, recuperando as ruas sombrias e solitárias e um certo lado decadente do espaço urbano. Como anteriormente referido, esta reinvenção de Gotham e Batman influenciou as criações de Tim Burton que, em Batman (1989) e Batman Returns (1992), investe numa atmosfera sombria que viria a redefinir o percurso do super-herói.

Para além de ser maioritariamente filmado em Londres, Batman evidencia-se pela influência da Art Deco[5] e pela atmosfera Gótica e escura, e que surge duplicada em Wayne/Batman, mas também nos vilões que partilham o grande ecrã com ele. A imagem produzida está longe da versão pop de 1966 e apresenta-se como um pesadelo distópico influenciado quer por uma imagética devedora da atmosfera noir, quer do Expressionismo Alemão (GONÇALVES, 2012, p. 12). Simultaneamente, e para lá destas influências, o papel de Anton Furst, designer de produção, foi essencial para a nova estética de Gotham City. A visão de Furst inspirou-se no livro The Metropolis of Tomorrow (1928), um livro de Hugh Ferriss - com visões das cidades do futuro - que o ajudou a desenvolver uma imagética de uma cidade desprovida do mundo natural, caracterizada por edifícios altos que cobriam as ruas envolvendo-as numa escuridão permanente. Chris Sims (2014), numa breve reflexão, nota ainda que, mais do que renovar a aura de Gotham City, Furst tentou criar o ambiente propício onde as personagens se encaixassem.

Contudo, é importante sublinhar que o mundo violento do filme de Burton estabelece uma relação com a Nova Iorque dos anos 80, um período de grande violência e instabilidade. Da mesma forma, a estética apresentada por Burton responde a um momento que responde às ansiedades do período final da Guerra Fria, como Upton descreve no seu estudo (UPTON, 2014, p. 2). Michael Keaton também viria a interpretar um Batman mais sério e sombrio, tal como os vilões que se revelariam distantes do filme 
de 1966. Esta relação que se adensa nos dois filmes de Burton, embora Batman Returns seja ligeiramente diferente em termos de estética, é essencial para compreender Gotham como um espaço que acolhe diferentes corpos fantásticos. Aliás, como notam Woinser e Boyns (2012, p. 220), é neste filme que Batman se assemelha aos vilões com quem luta, por este ser também uma figura marginal:

[...] Batman's world is clearly inhabited by deviants and villains of broad eccentricities; and Batman seems to fit right in. His perception that corrupt Gotham is not a "normal world" is expected, given the peculiarities of the characters who live there, but it also stands as justification for his own activities as a crime fighter who operates outside the law.

Esta dimensão de marginalidade, reconhecida pelo próprio Burton, viria a ser explorada ao máximo pela mão de Christopher Nolan: Batman, Ra's al Ghul, Joker ou Bane ocupam Gotham de diferentes formas e todos eles representam corpos que não respondem aos valores predominantes da sociedade e que, de uma forma ou de outra, são o espelho da organização da própria cidade. Antes de chegar a esta análise, afigurase necessário observar ainda uma outra adaptação. Se Burton procurava o potencial opressivo e incómodo de Gotham e, consequentemente, observava o lado obscuro do seu herói, Joel Schummacher apresentava um mundo diferente das obras de 1989 e 1992.

Batman Forever (1995) e Batman \& Robin (1997)[6] - sendo que o último foi considerado um insucesso quando comparado com os outros filmes de Batman mostravam uma Gotham bem diferente dos modelos anteriores, particularmente na primeira produção. Em Batman Forever (1995) a imagem da cidade dista do ambiente claustrofóbico de Batman Returns, como explica Muir:

The first frames of Batman Forever announces a drastic change had occurred in the world of Batman since the final frames of Batman Returns. Gotham city became more exaggerated, more neon and colorful, less noir, with giant deco statues dotting the computergenerated landscape. Instead of shadow and light, blacks and whites, the film was filled with garish red, bright greens and other stereotypical, so called "comic book" flourishes. (2008, p. 93)

As mudanças efectuadas pelo realizador e pela designer de produção Barbara Ling aproximavam Batman e Gotham do universo gráfico da banda desenhada. $\mathrm{O}$ espaço urbano futurístico de Batman Forever não estava envolto em sombras e emanava prosperidade: exagero nas cores, grandeza nos edifícios. Nesta Gotham, Batman é uma presença constante, pois como sugere William Bibbiani (2015), o super-herói é o salvador 
dos cidadãos e da cidade. Para Bibbiani (idem), Batman torna-se num espectáculo público que, por sua vez, transforma a cidade num local mais seguro e que acolhe as pessoas, mesmo havendo corrupção.

Assim, Batman é colocado como figura central no filme, inclusive no tipo de vilões que enfrenta, todos eles relacionados com a questão identitárias: Two-Face e The Riddler. Este último, aliás, desenvolve uma máquina capaz de ler mentes e descobre o segredo de Batman. Interessante ainda será notar que essa mesma máquina nasce nos laboratórios das Wayne Enterprises. Esta utilização indevida de projectos desenvolvidos via empresa/laboratório secreto de Wayne/Batman será um tema explorado nos próximos filmes realizados por Christopher Nolan.

A mudança constante da imagem de Gotham representa também ela uma alteração no super-herói, uma vez que este, enquanto símbolo da cidade, representa o fluxo dinâmico (URRICHIO, 2010, p. 139) que caracteriza a vitalidade de Gotham e em particular porque Batman está socialmente e culturalmente ligado ao espaço que habita. The Dark Knight Trilogy - Batman Begins (2005), The Dark Knight (2008) e The Dark Knight Rises (2012) -, de Christopher Nolan, dá continuidade a esta relação, mas trá-la para o período contemporâneo, pois a sua visão explora muitos dos problemas actuais das grandes metrópoles americanas. A Gotham recriada por este realizador é mais real e mais próxima do espectador, como aponta Reinhart:

The film's Gotham would end up reflecting Nolan's desire to present Batman and his world in a much more realistic manner than Warner's previous Batman films had. [...] Gotham City designs were inspired not by the fanciful images of Gotham found in Tim Burton's and Joel Schumacher's Batman films, but by real-life American cities such as New York and Chicago. (2013, p. 213)

Inspirado por estas cidades, Nolan criou uma paisagem familiar, na qual explora os potenciais perigos do espaço urbano, com especial atenção para o período pós-11 de Setembro, em particular para as ansiedades que resultaram dos ataques e dos medos contemporâneos, como regista Douthat:

Nolan's films are not the great art that some of their admirers imagine them to be, but they are effective dramatizations of the Way We Fear Now. Their villains are inscrutable, protean, appearing from nowhere to terrorize, seeking no higher end than chaos, no higher thrill than fear. Their hero fights, not for truth, justice and the American Way, but for a more basic form of civilizational order: He knows his society - his Gotham, our America - is decadent and corrupt in many ways, but he also knows that the alternatives are almost infinitely worse. (2012) 
De facto, o tipo de medo explorado na trilogia, tanto criado pelos vilões como pelo próprio super-herói, apoia-se na instalação do caos e do medo e, portanto, na desorganização da estrutura que suporta Gotham. Nolan associa Gotham a imagens de espaços reais, fazendo da cidade metáfora para o elevado sentimento geral de insegurança e vulnerabilidade que se seguiu aos ataques terroristas, bem como "a guerra contra o terrorismo", uma política de defesa que agravou a instabilidade já sentida após os acontecimentos daquela altura.

Neste sentido, o realizador convida os espectadores a olhar para Gotham como um microcosmos dos Estados Unidos (GILMORE, 2013), onde os nossos medos e expectativas são explorados. Enquanto personagem ligada directamente à cidade, Batman reflecte também estes temas, particularmente através da forma como cada filme explora a sua luta contra os vilões. Em Batman Begins enfrenta ataques terroristas; em The Dark Knight (2008) luta contra a instalação do caos e, finalmente, em The Dark Knight Rises (2012) enfrenta a destruição das estruturas económicas e sociais. O super-herói é, assim, o corpo que se opõe simbolicamente a outros corpos que representam o terror, o caos ou a instabilidade total. No entanto, é necessário considerar que: 1) para lutar contra estes vilões, Batman equipa-se de tecnologia que pode ser usada contra ele e contra a cidade, como acontece no primeiro e terceiro filmes; 2) as origens deste super-herói estão associadas a um dos grupos que aterroriza a cidade; 3) tal como os vilões também Batman está numa condição marginal. O próximo momento deste estudo considera estas e outras questões ao observar, numa análise breve, as visões contemporâneas de Gotham e Batman.

\section{Visões contemporâneas: a instalação do caos}

Em The Dark Knight Trilogy é notória a relação que Nolan estabelece entre Nova Iorque e Gotham, embora tenha filmado algumas das cenas em Chicago ou de se ter inspirado em cidades como Tóquio, por exemplo. Dado os acontecimentos, Nova Iorque tornou-se no local de desastre iminente, onde a tragédia pode acontecer a qualquer momento, como descreve Kevin Wetmore: “[New York became] the centre of post-9/11 horror [...] the site of primary destruction, mayhem and attacks. New York is 9/11 in a way that other sites are not" (2012, pp. 24-25). Isto é particularmente notório a nível cinematográfico onde é possível identificar várias referências visuais reminiscentes dos ataques. Filmes como The War of the Worlds (Steven Spielberg, 2005), I Am Legend (Francis 
Lawrence, 2007), The Mist (Frank Darabont, 2007) ou Cloverfield (Matt Reeves, 2008) são exemplos em que o espaço urbano doméstico nacional é destruído por diferentes ameaças e onde é possível estabelecer uma relação directa e indirecta com Nova Iorque. Na maior parte destas narrativas, o governo é incapaz de responder à ameaça ao espaço doméstico, expondo assim as fragilidades nacionais, ao mesmo tempo que sublinha o elevado sentimento de insegurança.

No caso de Batman Begins (2005), o primeiro de três produções cinematográficas, este pode ser considerado um dos primeiros filmes a responder visualmente aos eventos do 11 de Setembro. Gotham City é uma cidade marcada pelo medo e violência, na qual o terrorismo se apresenta como "a forma suprema do mal" (FEBLOWITZ, 2009, p. 1 tradução minha). Carmine Falcone, Crane/Scarecrow, Ra's al Ghul \& The League of Shadows todos usam formas diferentes da implementação do medo como arma, o que contribui para a existência de um espaço urbano que está sob constante ameaça. Falcone controla a cidade através da violência física e da corrupção policial. Jonathan Crane, através da sua persona Scarecrow, realiza experiências com um gás alucinante para implementar o medo. Ra's al Ghul \& The League of Shadows, por sua vez, representam uma ameaça diferente para a cidade. Tal como o seu nome indica, esta organização opera na sombra (FEBLOWITZ, 2009, p. 6), servindo-se da teatralidade e da ilusão para destruir e reconstruir as nações que consideram corruptas.

A Gotham de Nolan, tal como em alguns dos casos anteriores, é uma cidade com profundas desigualdades sociais, com a Wayne Tower enquanto símbolo de riqueza e The Narrows de pobreza. Este contraste é acentuado quando a Liga pretende destruir a ponte que estabelece a conexão entre ricos e pobres, prolongando, desta forma, a disparidade entre as classes na cidade e perpetuando a injustiça, a pobreza e o crime. A Liga promove, assim, uma cultura do medo que ecoa no contexto das ansiedades contemporâneas da nação Americana. Este medo não é provocado apenas pelas acções dos vilões, mas por aquilo que eles representam. Assim, Falcone surge associado à ideia de corrupção, Scarecrow ao lado sombrio da psique humana e, finalmente, Ra's al Ghul e a Liga à constante e iminente sensação de apocalipse que se instalou nos últimos anos. Ao mesmo tempo, o próprio Batman também provoca medo nos residentes de The Narrows, em particular por estes estarem sob efeito do gás de Scarecrow. Assim, é interessante olhar para o corpo de Batman como fantástico, mas também ele aterrador e esse aspecto é reconhecido por um outro vilão, talvez aquele que melhor representa a completa instalação do caos: Joker. 
Análoga à representação de Ra's al Ghul enquanto personificação de uma cidade caracterizada pelo medo e paranóia Joker é um vilão bastante mais imprevisível (FEBLOWITZ, 2009, p. 6) que o seu predecessor. Enquanto o primeiro tem algum sentido de justiça - Joker - tal como o seu nome indica escarnece desse mesmo conceito, uma vez que a sua acção sublinha a natureza impressível das coisas. Às mãos de Joker, Gotham não tem qualquer sentido de ordem social, como explica Feblowitz:

Contrary to the original Joker and the Joker of Burton's Batman, Nolan's Joker lacks both a motivation and an identity. This radically enigmatic presentation of the Joker deprives the audience of a locus of control; with no comprehensible motivations or identity, the character is an impenetrable riddle, desiring only terror and mayhem. The post-9/11 Joker is interested in neither wealth nor power nor revenge. (2009, p. 6)

Esta é, no fundo, uma personagem à deriva que, desprovida de uma identidade concreta, representa o "outro" que põe em causa os valores sociais, morais bem como a estabilidade da cidade. Para tal, Joker vai lentamente corrompendo as várias estruturas que suportam a cidade. Aqueles que lhe resistem ou acabam mortos ou são forçados a quebrar os seus valores. É o caso de Gordon, Harvey Dent ou Batman, que para o enfrentar é obrigado a recorrer a métodos de vigilância pouco ortodoxos do ponto de vista ético.[7]

Além disso, o vilão reconhece o seu papel e assume a sua identidade de figura marginal e fá-lo também em relação a Batman, tal como anteriormente referido:

The Joker: Don't talk like one of them. You're not! Even if you'd like to be. To them, you're just a freak, like me! They need you right now, but when they don't, they'll cast you out, like a leper! You see, their morals, their code, it's a bad joke. Dropped at the first sign of trouble. They're only as good as the world allows them to be. I'll show you. When the chips are down, these... these civilized people, they'll eat each other. See, I'm not a monster. I'm just ahead of the curve. (The Dark Knight, 2008)

Ao colocar em perspectiva a marginalidade de Batman, Joker sublinha a aproximação do herói aos vilões, aos seus corpos disformes e aterradores. Esta comparação é essencial para entender Batman e a sua ligação a Gotham: apesar de ser o seu herói, este rapidamente também se pode tornar no vilão, tal como irá acontecer no início do terceiro filme da trilogia.

Joker excede todas as fronteiras de modo a quebrar a ordem estabelecida. As suas acções imprevisíveis têm como propósito um regresso a um estado mais primitivo e, como tal, altamente instável. A luta de Batman nas sombras é disso exemplo. Para poder 
combater estas figuras terá de se aproximar delas necessariamente. Na verdade, e apesar de ser uma figura marginal, Batman continua a busca incessante pela verdade e justiça, mesmo que, por vezes, isso implique a quebra de regras. Já Joker é o reflexo da potencial instabilidade de Gotham, uma metáfora para o espaço urbano como o local de violência e terror. O último filme da trilogia não é excepção, embora apresente uma ameaça nova.

The Dark Knight Rises (2012) regressa com The League of Shadows, liderados por Talia al Ghul e Bane que invadem Gotham, metáfora para Manhattan. O mercenário Bane - também ele um corpo diferente -, consciente da condição frágil de Gotham, apodera-se da cidade ao minar a ordem estabelecida. ${ }^{[8]}$ Nas mãos de Bane a cidade fica despedida de valores democráticos ${ }^{[9]}$ e, paralelamente, de valores morais. $\mathrm{O}$ vilão quebra física e espiritualmente a cidade e Batman usando aquilo que Zizek (2012) define como uma estratégia político-ideológica: 1) o colapso financeiro das empresas Wayne e da cidade; 2) a denúncia de um sistema injusto e a revelação da verdade em relação a Harvey Dent; 3) finalmente, a constante ameaça de terror e instabilidade.

No início do filme, Bane invade a bolsa de Nova Iorque (numa referência directa ao movimento "Occupy Wall Street"). Esta acção mostra que, ao contrário dos outros vilões, ele vê potencial na queda económica de Gotham, o que lhe permite devolver o poder ao povo e, ao mesmo tempo, controlar a cidade. Esta atitude reflecte um processo revolucionário que denuncia as desigualdades sociais causadas pelo sistema e pela crise económica. Da mesma forma, Bane é responsável por expor a verdade em relação ao que aconteceu a Harvey Dent, retirando à cidade um herói e os valores por ele representados. Deste modo, a cidade e os seus habitantes apercebem-se da ilusão criada por Gordon e Batman. Este último é quebrado por Bane quer espiritualmente, quer fisicamente e a sua derrota espelha a derrota de Gotham e a vitória dos terroristas, especialmente Talia que, servindo-se de Bane e Batman, pretende detonar uma bomba nuclear e provocar a aniquilação total da cidade. Interessante será notar que esta arma é providenciada pelas Wayne Enterprises: assim, a tecnologia criada pela empresa e para Batman tem uma dupla utilização (para o bem e para o mal).

Tal como nos outros filmes, as diferentes ameaças apresentadas pelos vilões transformam a cidade num "espectáculo do terror", como nota Gilmore (2013), particularmente visível na primeira parte do filme. As várias imagens das detonações do estádio e dos túneis representam a ausência da lei e um ataque directo aos valores Americanos. A partir deste momento, e com a Liga a emergir literalmente das sombras, os espectadores são confrontados com imagens que intensificam as ansiedades 
provocadas pelos ataques terroristas. Ao usar imagens de uma cidade real para representar uma cidade imaginária Nolan sublinha o fino véu que separa a ficção e a realidade.

A segunda parte do filme, todavia, dá voz à reacção de Batman, e consequentemente da cidade, contra os vilões e a sua política de terror. O renascimento de Batman serve de metáfora para toda a comunidade de Gotham: à medida que este vai lutando contra os vilões, também os seus habitantes o fazem, ultrapassando assim o medo e ansiedade anteriores. Esta é também a confirmação de que a sobrevivência de Gotham depende de vários heróis de forma a permanecer longe de um domínio caracterizado pelo estado permanente de terror e caos.

The Dark Knight Rises explora muitas das ansiedades criadas pelos eventos do 11 de Setembro de 2001, mas também por uma década de luta contra o terrorismo, e apresenta um certo fascínio com a destruição do espaço urbano doméstico. Neste sentido, Gotham singulariza-se como um espaço que facilmente pode sucumbir aos poderes da anarquia e devastação. A cena final, com a possibilidade de aniquilação total, é representativa de um trauma que, 15 anos depois, ainda está a ser negociado de diferentes formas, mas que pode ser enfrentando em comunidade. Na trilogia de Nolan é notório o modo como, contrariamente aos filmes anteriores e como revela James $\mathrm{N}$. Gilmore (2015, p. 54), a cidade está sob constante ameaça de destruição. Consequentemente, isto também significa que o papel do super-herói, mais do que salvar a cidade da destruição, é o de reestabelecer o equilíbrio. Sendo esse equilíbrio precário, e de forma a evitar a total imersão nas sombras, Gotham está constantemente a necessitar de um herói que a compreenda.

\section{Conclusão: "what I do defines me"}

A trilogia de Nolan articula uma nova relação entre o espaço urbano, o cinema, o real e Batman. Como tentei demonstrar ao longo deste estudo a imagem de Gotham e Batman reflecte as ansiedades do seu tempo. Por outro lado, a cidade e o seu herói estão intimamente ligados. Tentou-se apresentar o modo como diferentes artistas e realizadores olharam para a maneira como espelharam e projectaram o real.

Gotham City, como Batman, permanece um símbolo com uma identidade em constante mudança (URRICHIO, 2010, p. 31). O percurso explorado nesta análise 
percorre diferentes fases desta identidade revelando, assim, os diferentes corpos que habitam a cidade, mas também o modo como esta os tem acolhido. Um momento chave para a compreensão desta relação surge no primeiro filme da trilogia realizada por Nolan em que Batman revela a sua verdadeira identidade a Rachel: "It's not who I am underneath, but what I do that defines me" (Batman Begins, 2005). As acções de Batman, enquanto protector da cidade, definem a sua identidade, mas também são exemplo do tipo de equilíbrio que pretende criar na cidade.

Assim, será importante sublinhar o final da trilogia em que Batman parece retirar-se, mas não sem deixar um legado. Tal como referido na secção anterior, Gotham está em constante necessidade de um herói. O renascimento de Batman em The Dark Knight Rises origina o nascimento de outros heróis e talvez por isso a cidade em transformação necessite de um outro corpo, e Robin surja das cinzas de uma outra, a sua cidade, disposto a continuar o trabalho iniciado em 1939.

\section{Notas de rodapé}

[1] Note-se que este ensaio reconhece a importância de Batman enquanto anti-herói, especialmente no que toca às mais recente adaptações. Contudo, este não será um tema aprofundado neste estudo.

[2] Note-se, no entanto, que em Burton on Burton (2006), o autor refere que uma das suas grandes influências para a criação de Batman (1989) foi The Killing Joke (1988), de Alan Moore.

[3] Washington Irving utilizou o termo Gotham City pela primeira vez em 1807 como forma de satirizar Nova Iorque. O criador Bill Finger optou pela utilização deste nome para a cidade que criou.

[4] A primeira adaptação conhecida de Batman é de 1943 e divide-se em 15 episódios. O mesmo acontece na adaptação de 1949, Batman and Robin. Ambas tinham como principais protagonistas Batman e Robin. Em 1960 também surgiu uma adaptação para televisão, que viria a ser transformada em filme em 1966.

[5] Como nota Chris Sims (2014), a sensibilidade e estética Art Deco da adatpação de 1989 era visível nas personagens secundárias, cujo estilo recuava até aos anos 40 - de forma a ecoar os primeiros números de Batman.

[6] É interessante notar que em ambos os casos os actores escolhidos para interpretar Batman mudaram nos dois filmes: Michael Keaton foi substituído Val Kilmer no filme de 1995 e este, por sua vez, foi trocado por George Clooney, o que também mostra uma alteração na fisicalidade e imagem de Batman. Christian Bale, actor que viria a participar nos três filmes de Nolan também apresenta características diferentes dos outros actores, dando uma nova vida a Batman.

[7] Esta é, aliás, uma referência directa à política de guerra contra o terror instaurada por Bush. [8] Note-se como Bane veste um casaco de pele durante grande parte do filme, o que pode ser encarado como uma referência ao seu lado animal, um lobo. O uso da máscara, de alguma forma, alude também a essa ideia, mas é ao mesmo tempo uma característica que evidencia a sua diferença corporal em relação a outros.

[9] Um dos exemplos será a criação de um tribunal e de uma nova forma de aplicar a lei com Scarecrow como principal responsável. 


\section{Referências}

AHRENS, Jorn; METELING, Arno (eds.). Comics and the City: Urban Space in Print, Picture and Sequence. London \& New York: Bloomsbury Publishing, 2010, 288 pp.

BIBBIANI, William. How to Make the Joel Schumacher Batman Movies Work For You. Craven, 5 de Fevereiro, 2015.

Disponível em: <http://www.craveonline.com/entertainment/805933-make-joelschumacher-batman-movies-work>. Acedido em 12 de Agosto de 2016.

BROOKER, Will. Batman Unmasked: Analysing a Cultural Icon. London \& New York: Bloomsbury Publishing, 2000, 358 pp.

. Hunting the Dark Knight: Twenty-First Century Batman. London: I.B. Tauris, 2012, $272 \mathrm{pp}$.

BURKE, Liam. The Comic Book Film Adaptation: Exploring Modern Hollywood's Leading Genre. Mississippi: University Press of Mississippi, 2015, 384 pp.

COGLE, Jarred. Christopher Nolan's Gotham City and Global Cinema Space. The Mediated City Conference. London, Disponível em: <http://architecturemps.com/wpcontent/uploads/2013/09/mc_conference_cogle_jarrad.pdf $>$. Acedido em: 12 de Agosto de 2016.

DOUHAT, Ross. The Way We Fear Now. The New York Times, 22 de Julho, 2012. Disponível em: <http://www.nytimes.com/2012/07/22/opinion/sunday/douthatthe-way-we-fear-now.html?_r=3\&>. Acedido em 15 de Agosto de 2016.

FEBLOWITZ, Joshua C. The Hero We Create: 9/11 and the Reivention of Batman. Inquiries Journal: Social Sciences, Arts and Humanities, vol. 1, número 12, 2009. Disponível em: <http://www.inquiriesjournal.com/articles/104/the-hero-we-create911-the-reinvention-of-batman>. Acedido em: 15 de Agosto de 2016.

GILMORE, James. Absolute Anxiety Test: Urban Wreckage in The Dark Knight Rises. Mediascape: UCLA'S Journal of Cinema and Media Studies, Outono 2012. Disponível em: <http://www.tft.ucla.edu/mediascape/Fall2013_TheDarkKnightRises.html>. Acedido em: 24 de Agosto de 2016.

GILMORE, James N. A Eulogy of the Urban Superhero: The Everyday Destruction of Space in the Superhero Film. PETROVIC, Paul. Representing 9/11: Trauma, Ideology, and Nationalism in Literature, Film, and Television. London \& New York: Rowman \& Littlefield, 2015, pp. 53-65.

GONÇALVES, Vilson André Moreira. Acima da Cidade, uma Gárgula em Movimento: Vislumbres do Urbano em Batman de Tim Burton. Razón Y Palabra: Primera Revista Electrónica en América Latina Especializada en Comunicación, Número 80, AgostoOutubro, 2012. Disponível em:

<http:/ /www.razonypalabra.org.mx/N/N80/V80/12_Moreira_V80.pdf>. Acedido em: 12 de Agosto de 2016. 
MUIR, John Kenneth. Trading Card Close-Up: \#11: Batman: The Movie (1966). John Kenneth Muir's Reflections on Cult Movies and Classic TV, February 20. Disponível em: <http:/ / reflectionsonfilmandtelevision.blogspot.pt/2008/02/trading-card-closeup-11-batman-movie.html>. Acedido em: 20 de Agosto de 2016.

PUGH, Emily. Architecture, Politics, and Identity in Divided Berlin. Pittsburgh, P.: University of Pittsburg Press, 2014, 440 pp.

SIMS, Chris. The Avant-Garde of the New Aesthetics: Batman 89', Destroyer and the Changed Face of Gotham City. Comics Alliance, 24 de Junho de 2014. Disponível em: $<$ http:/ / comicsalliance.com/ batman-89-anton-furst-gotham-city-destroyer-grantbreyfogle-aparo-design/>. Acedido em: 20 de Agosto de 2016.

$\mathrm{TOH}$, Justin. The Tools and the Toys of (the) War (on Terror): Consumer desire, military fetiche and regime change in Batman Begins. Scan: Journal of Media Arts and Culture. Disponível em:

<http:// scan.net.au/scan/journal/display.php?journal_id=129>. Acedido em: 20 de Agosto de 2016.

URRICHIO, William. The Batman's Gotham City ${ }^{\mathrm{TM}}$ : Story, Ideology, Performance. AHRENS, Jorn; METELING, Arno (editors). Comics and the City: Urban Space in Print, Picture and Sequence. London \& New York: Continuum, 2010, pp. 119-133.

UPTON, Bryn. Hollywood and the End of the Cold Era: Signs of Cinematic Change. London \& New York: Rowman \& Littlefield, 2014, 208 pp.

WETMORE, Kevin. Post-9/11 Horror in American Cinema. London \& New York: Bloomsbury, 2012, 248 pp.

WHITE, Mark D.; ARP, Robert (Eds.). Batman and Philosophy. Hoboken, N.J.: John Wiley \& Sons, 2008, 294 pp.

WONSER, Robert; BOYNS, David. The Caped Crusader: What Batman Films Tell Us about Crime and Deviance. SUTHERLAND, Jean-Anne; FELTEY, Kathryn M. (editors). Cinematic Sociology: Social Life in Film. London: Sage, 2012, pp. 231-227.

ZIZEK, Slavoj. The Politics of Batman. New Statestman, 23 de Agosto de 2012. Disponível em: <http://www.newstatesman.com/culture/culture/2012/08/slavojžižek-politics-batman>. Acedido em: 20 de Agosto de 2016.

\section{Filmografia}

Batman, Dir. Lambert Hillyer. Columbia Pictures Corporation, 1943.

Batman and Robin, Dir. Spences Gordon Bennet, Columbia Pictures Corporation, 1949. Batman, Criado por William Dozier, Greenway Productions, 1966-1968. - Série de Televisão.

Batman: The Movie, Dir. Leslie H. Martinson, 20 th Century Fox, 1966.

Batman, Dir. Tim Burton, Warner Bros., 1989.

Batman Returns, Dir. Tim Burton, Warner Bros., 1992. 
Batman Forever, Dir. Joel Schumacher, Warner Bros., 1995.

Batman E Robin, Dir. Joel Schumacher, Warner Bros., 1997.

Batman Begins, Dir. Christopher Nolan, Warner Bros., 2005.

Batman: The Dark Knight, Dir. Christopher Nolan, Warner Bros., 2008.

Batman: The Dark Knight Rises, Dir. Christopher Nolan, Warner Bros., 2012.

Cloverfield, Dir. Matt Reeves, Paramount Pictures, 2008.

I Am Legend, Dir. Francis Lawrence, Warner Bros., 2007.

The Mist, Dir. Frank Darabont, Weinstein Company, 2007.

The War of the Worlds, Dir. Steven Spielberg, Paramount Pictures, 2005.

Recebido em 08/12/2016

Aceito em 11/02/2017. 